\title{
Osthole induces lung cancer cell apoptosis through inhibition of inhibitor of apoptosis family proteins
}

\author{
XIAO-MAN XU ${ }^{1}$, MAN-LI ZHANG ${ }^{1}$, YI ZHANG ${ }^{2}$ and LI ZHAO $^{1}$ \\ Departments of ${ }^{1}$ Respiratory Medicine and ${ }^{2}$ Geriatrics, Shengjing Hospital of China Medical University, \\ Shenyang, Liaoning 110004, P.R. China
}

Received July 13, 2015; Accepted September 9, 2016

DOI: $10.3892 / \mathrm{ol} .2016 .5170$

\begin{abstract}
In the present study, we investigated the effects and mechanisms of Osthole on the apoptosis of non-small cell lung cancer (NSCLC) cells and its synergistic effect with Embelin. Our results revealed that treatment with both Osthole and Embelin inhibited cell proliferation. Notably, combination treatment of Osthole and Embelin inhibited cell proliferation more significantly compared with monotherapy. In addition, morphological analysis and Annexin V/propidium iodide analysis revealed that the combination of Osthole and Embelin enhanced their effect on cell apoptosis. We further examined the effect of Osthole on the expression of inhibitor of apoptosis protein (IAP) family proteins. That treatment of A549 lung cancer cells with various concentrations of Osthole was observed to decrease the protein expression of X-chromosome-encoded IAP, c-IAP1, c-IAP2 and Survivin, and increase Smac expression in a dose-dependent manner. Furthermore, it was noted that Osthole or Embelin alone increased the expression of BAX, caspase-3, caspase-9, cleaved caspase-3 and cleaved caspase-9, and decreased Bcl-2 levels following treatment. Osthole and Embelin combination treatment had a synergistic effect on the regulation of these proteins. In conclusion, our study demonstrated that Osthole inhibited proliferation and induced the apoptosis of lung cancer cells via IAP family proteins in a dose-dependent manner. Osthole enhances the antitumor effect of Embelin, indicating that combination of Osthole and Embelin has potential clinical significance in the treatment of NSCLC.
\end{abstract}

\section{Introduction}

Lung cancer is the leading cause of cancer-related mortality in the world, with non-small cell lung cancer (NSCLC)

Correspondence to: Dr Li Zhao, Departments of Respiratory Medicine, Shengjing Hospital of China Medical University, 36 Sanhao Road, Shenyang, Liaoning 110004, P.R. China E-mail: cmuzhaol@126.com

Key words: Osthole, Embelin, inhibitor of apoptosis proteins accounting for $\sim 80 \%$ of cases (1). Despite advances in the management of NSCLC, improvements in survival are marginal and the overall prognosis of patients remains poor $(2,3)$. Defects in the normal apoptosis machinery have been implicated in the resistance of cancer cells to a wide variety of current anticancer drugs (4). Therefore, identifying new agents that induce apoptosis in cancer cells offers novel and potentially useful approaches to improve patient responses to conventional chemotherapy $(5,6)$.

Osthole, 7-methoxy-8-(3-methyl-2-butenyl)coumarin, a natural compound, may be extracted from Cnidium monnieri and other medicinal plants (7). Previous studies have revealed that Osthole exhibits various pharmacological activities, including anti-inflammation (8), anti-allergy (9), anti-oxidation (10), estrogen-like (11) and anti-hepatitis (12) effects. Furthermore, accumulating evidence indicates that Osthole confers antitumor effects by inhibiting tumor cell growth and inducing apoptosis (13-15). However, the effects of Osthole on the apoptosis of NSCLC and the possible mechanisms behind it remain unclear.

The inhibitor of apoptosis proteins (IAPs) are significant intrinsic cellular inhibitors of apoptosis (16-20). The human IAP family contains eight proteins: c-IAP1, c-IAP2, NAIP, Survivin, X-chromosome-encoded IAP (XIAP), Bruce, ILP-2 and Livin (21). To date, the overexpression or dysfunction of IAPs have been detected in various cancers (22-24). Therefore, identifying new agents targeting IAPs is essential for cancer drug development. Embelin is one such promising compound targeting XIAP. Embelin, a plant-based benzoquinone derivative (25), has been identified as a cell-permeable, small molecular weight inhibitor of XIAP by virtue of its interaction with the BIR3 domain (26). A number of cancers, including NSCLC (27), express elevated levels of XIAP and become refractory to apoptosis $(23,28)$; however, treatment with Embelin alone or in combination with other anticancer drugs was observed to sensitize them towards apoptosis $(26,29)$.

The present study was performed to evaluate the effects of Osthole on cell viability and apoptosis in NSCLC cells and to determine whether Osthole-mediated apoptosis is dependent on IAP proteins. Furthermore, we evaluated the combined effects of two herbal medicines, Osthole and Embelin, on the apoptosis of NSCLC cells in vitro, exploring the possibility of a combined clinical application. 


\section{Materials and methods}

Reagents. RPMI-1640, trypsin, penicillin and streptomycin were purchased from Biological Industries (Kibutz Beit Haemek, Israel). Fetal bovine serum (FBS) was purchased from Solarbio Science \& Technology (Beijing, China). 3-(4,5-dimethyl thiazol-2yl)-2,5-diphenyltetrazolium bromide (MTT), dimethyl sulfoxide (DMSO), propidium iodide (PI), and Hoechst 33342 were purchased from Sigma-Aldrich (St. Louis, MO, USA). An Annexin V-fluorescein isothiocyanate (FITC) and PI double staining kit were purchased from Key Gene (Nanjing, China). Osthole and Embelin were purchased from the National Institute for the Control of Pharmaceutical and Biological Products (Beijing, China), Stock solution $(50 \mathrm{mM})$ was prepared by dissolving Osthole or Embelin in DMSO and stored at $-20^{\circ} \mathrm{C}$. Antibodies were purchased from Santa Cruz Biotechnology, Inc. (Dallas, TX, USA). All other reagents were procured locally.

Cell culture. The human lung cancer cell line A549 was purchased from China Center for Type Culture Collection (Wuhan, China) and cultured in RPMI-1640 medium supplemented with $10 \%$ FBS, $100 \mathrm{U} / \mathrm{ml}$ penicillin and $100 \mu \mathrm{g} / \mathrm{ml}$ streptomycin at $37^{\circ} \mathrm{C}$ in $5 \% \mathrm{CO}_{2}$. Cells were grown on sterile tissue culture dishes and digested using $0.25 \%$ trypsin.

MTT assay. A549 cells (5x103/well) were plated in 96-well plates, cultured overnight, and then treated with Osthole $(100 \mu \mathrm{M})$ and Embelin $(50 \mu \mathrm{M})$ alone or in combination for $24 \mathrm{~h}$, respectively. Corresponding DMSO or culture medium was used as an empty control. Briefly, $20 \mu 15 \mathrm{mg} / \mathrm{ml}$ MTT solution was added to each well and incubated for $4 \mathrm{~h}$ at $37^{\circ} \mathrm{C}$, then the supernatant was removed from each well, and DMSO $(150 \mu \mathrm{l})$ was added to dissolve the formazan crystals. Absorbance was measured at $570 \mathrm{~nm}$. Data were obtained from triplicate wells per condition and the results are representative of at least three independent experiments.

Flow cytometry. A549 cells $\left(5 \times 10^{5} /\right.$ well) were seeded in six-well plates and allowed to attach overnight. Then, cells were treated with Osthole $(100 \mu \mathrm{M})$ and Embelin $(50 \mu \mathrm{M})$ alone or in combination for $24 \mathrm{~h}$, respectively, and harvested by $0.25 \%$ trypsin. The cells were then washed twice with chilled phosphate-buffered saline (PBS), then resuspended in $250 \mu 1$ binding buffer and adjusted to $1 \times 10^{6} / \mathrm{ml}$. Staining solution containing Annexin V/FITC and PI was added to the cell suspension. Following incubation in the dark for $30 \mathrm{~min}$, the cells were analyzed by a FACSCalibur flow cytometer (BD Biosciences, Franklin Lakes, NJ, USA).

Fluorescence microscopy. A549 cells $\left(5 \times 10^{5}\right)$ were seeded into six-well plates and cultured overnight, and then incubated with Osthole $(100 \mu \mathrm{M})$ and Embelin $(50 \mu \mathrm{M})$ alone or in combination for $24 \mathrm{~h}$, respectively. Cells were washed twice with PBS and fixed with cold methanol and acetic acid $(3 / 1, v / v)$ at $4^{\circ} \mathrm{C}$. Then, cell preparations were washed in PBS and stained with Hoechst $33342(1 \mathrm{mg} / \mathrm{ml})$ for $30 \mathrm{~min}$ in the dark before being washed again in PBS and finally observed with a fluorescence microscope (x400, Nikon Corporation, Tokyo, Japan).

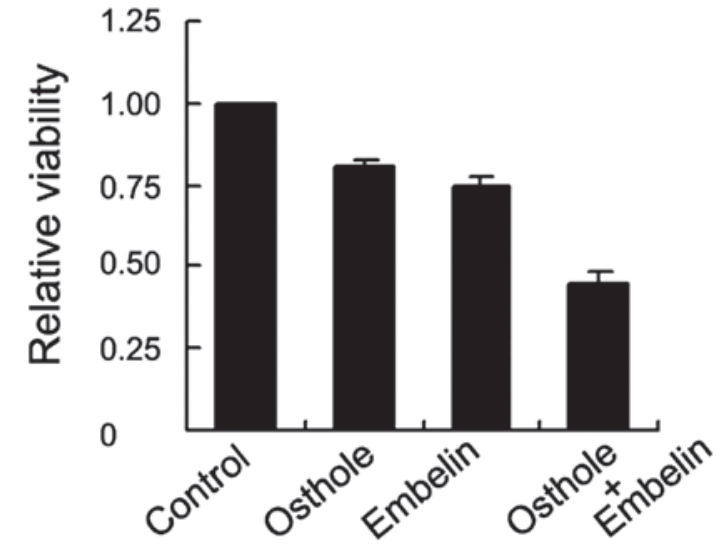

Figure 1. Combined effect of Osthole and Embelin on viability of A549 cells. Osthole $(100 \mu \mathrm{M})$ and Embelin $(50 \mu \mathrm{M})$ treatment alone inhibited cell proliferation. However, combination treatment of Osthole and Embelin inhibited cell proliferation more significantly compared with monotherapy.

Western blot analysis. Treated cells were analyzed by western blot analysis. Briefly, the cell pellets were resuspended in lysis buffer at $4^{\circ} \mathrm{C}$ for $1 \mathrm{~h}$. Following centrifugation at $12,000 \mathrm{x}$ g for $20 \mathrm{~min}$, the supernatant was collected and stored at $-80^{\circ} \mathrm{C}$. A total of $50 \mu \mathrm{g}$ protein was separated using $10 \%$ sodium dodecyl sulphate-polyacrylamide gel electrophoresis and then transferred to a polyvinylidene fluoride membrane. The membrane was blocked with $5 \%$ non-fat milk and incubated overnight at $4{ }^{\circ} \mathrm{C}$ with antibodies against Bcl-2, BAX, caspase-3, caspase-9, cleaved caspase-3, cleaved caspase-9, XIAP, c-IAP1, c-IAP2, survivin and Smac. Following incubation with peroxidase-conjugated anti-mouse/rabbit IgG (Santa Cruz Biotechnology, Inc.) at $37^{\circ} \mathrm{C}$ for $2 \mathrm{~h}$, proteins were visualized using enhanced chemiluminescence (Pierce Biotechnology, Inc., Rockford, IL, USA) and detected using a bioimaging system (UVP Inc., Upland, CA, USA).

Statistical analysis. SPSS 13.0 software (SPSS, Inc., Chicago, IL, USA) was used for all statistical analyses. Data are expressed as the means \pm standard deviation. Statistical correlation of data was checked for significance by analysis of variance and Student's t-test. $\mathrm{P}<0.05$ was considered to indicate a statistically significant difference.

\section{Results}

Combined effect of Osthole and Embelin on viability of A549 cells. To evaluate the cytotoxicity of Osthole and Embelin alone and in combination on lung cancer cells, A549 cells were treated with Osthole $(100 \mu \mathrm{M})$ and Embelin $(50 \mu \mathrm{M})$ alone or in combination for $24 \mathrm{~h}$, respectively, and the proliferation rate was examined using MTT assay (Fig. 1). Our results revealed that Osthole and Embelin treatment alone inhibited cell proliferation. Notably, however, the combination treatment of Osthole and Embelin inhibited cell proliferation more significantly compared with monotherapy.

Combined effect of Osthole and Embelin on apoptosis. To investigate the effect of Osthole and Embelin alone and in combination on the apoptosis of lung cancer cells, A549 cells were treated with Osthole $(100 \mu \mathrm{M})$ and Embelin $(50 \mu \mathrm{M})$ alone or in combination as indicated above. Morphological 


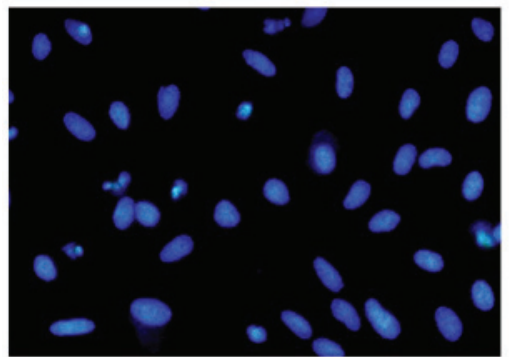

Control

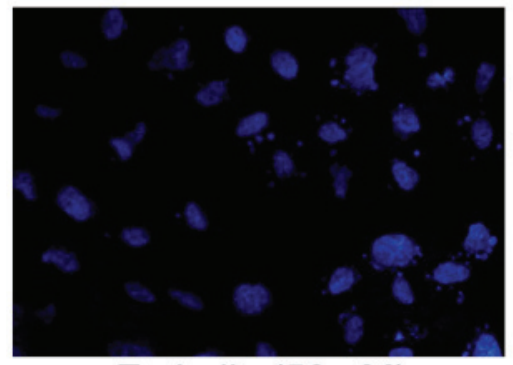

Embelin $(50 \mu \mathrm{M})$

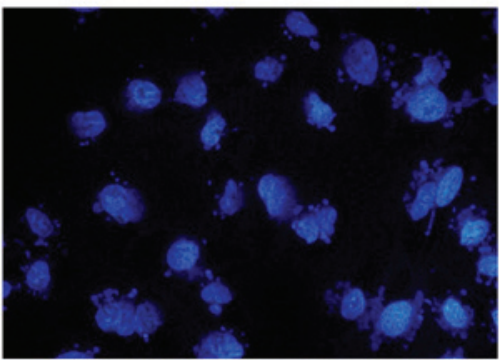

Osthole $(100 \mu \mathrm{M})$

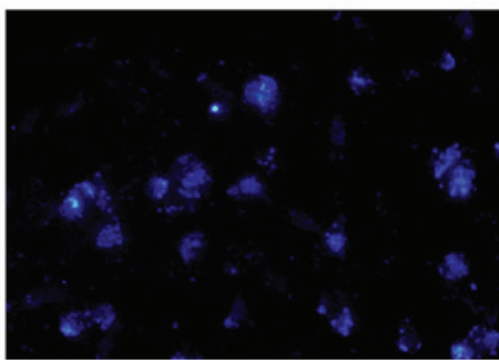

Osthole+Embelin

Figure 2. Morphology changes caused by Osthole and Embelin. Osthole or Embelin alone caused morphological alteration in A549 cells. Typical morphological changes including condensation of chromatin, karyopyknosis and nuclear fragmentation were observed. Cell apoptosis was observed by Hoechst 33342 staining. Notably, compared with cells treated with a single agent, cells exposed to combined Osthole and Embelin treatment exhibited a higher apoptosis rate. Magnification, x400.

changes were detected using fluorescence microscopy and the apoptosis rate was evaluated by Annexin V/PI staining.

As shown in Fig. 2, Osthole and Embelin alone caused morphological alteration in A549 cells. Typical morphological changes including condensation of chromatin, karyopyknosis and nuclear fragmentation were observed. Notably, compared with cells treated with a single agent, cells exposed to the combined Osthole and Embelin treatment exhibited a higher apoptosis rate.

Annexin V/PI flow cytometry analysis indicated that cells receiving the combined treatment had higher levels of apoptosis compared with cells treated with Osthole or Embelin alone. As shown in Fig. 3, both Osthole or Embelin increased cell apoptosis. The percentage of apoptotic cells induced by Osthole and Embelin was $4.26 \pm 0.41 \%$ in the control group, $18.31 \pm 2.67 \%$ in the Osthole group and $14.76 \pm 1.05 \%$ in the Embelin group. In contrast, the apoptosis percentage induced by the combination treatment was $34.36 \pm 2.98 \%$. These results demonstrated that Osthole and Embelin had a synergistic effect on apoptosis in lung cancer cells.

Osthole regulates the IAP pathway in a dose-dependent manner. The effect of Osthole was further investigated on IAP proteins, which play a significant role in intrinsic programmed cell death. A549 cells were treated with various concentrations of Osthole $(0,50,100$ and $150 \mu \mathrm{M})$ for $24 \mathrm{~h}$, and then the expression levels of IAP family members including XIAP, c-IAP1, c-IAP2, Survivin and Smac were determined by western blot analysis. The protein levels of XIAP, c-IAP1, c-IAP2 and Survivin were decreased, while Smac was increased following Osthole treatment (Fig. 4). Notably, the inhibitory effect of Osthole on XIAP, c-IAP1, c-IAP2 and Survivin increased as the dose increased. Conversely, the expression of Smac increased as the dose of Osthole increased.
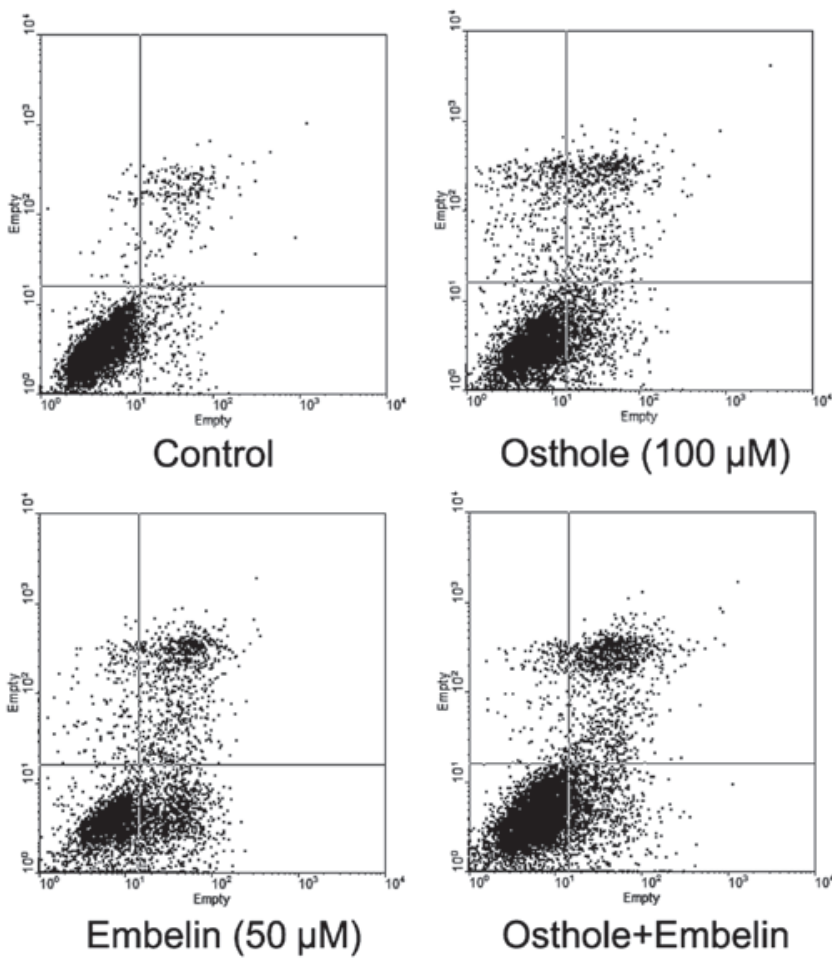

Figure 3. Combined effect of Osthole and Embelin on apoptosis Annexin V/propidium iodide flow cytometry analysis indicated that the percentage of apoptotic cells induced by Osthole or Embelin was $4.26 \pm 0.41 \%$ (control group), 18.31 $\pm 2.67 \%$ (Osthole group) and 14.76 $\pm 1.05 \%$ (Embelin group). The apoptosis percentage induced by the combination treatment was $34.36 \pm 2.98 \%$.

Combined effect of Osthole and Embelin on apoptosis-related proteins. To explore the possible mechanisms by which Osthole and Embelin regulate apoptosis, a panel of apop- 


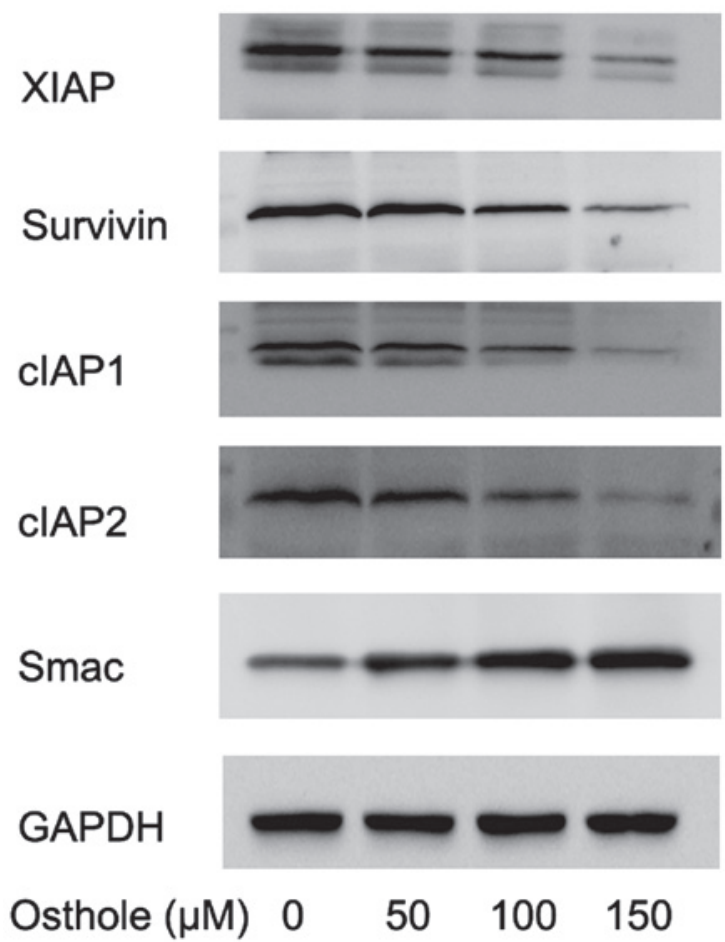

Figure 4. Osthole regulates inhibitor of apoptosis protein (IAP) family proteins. The protein levels of XIAP, c-IAP1, c-IAP2 and Survivin were decreased while Smac was increased following Osthole treatment in a dose-dependent manner.

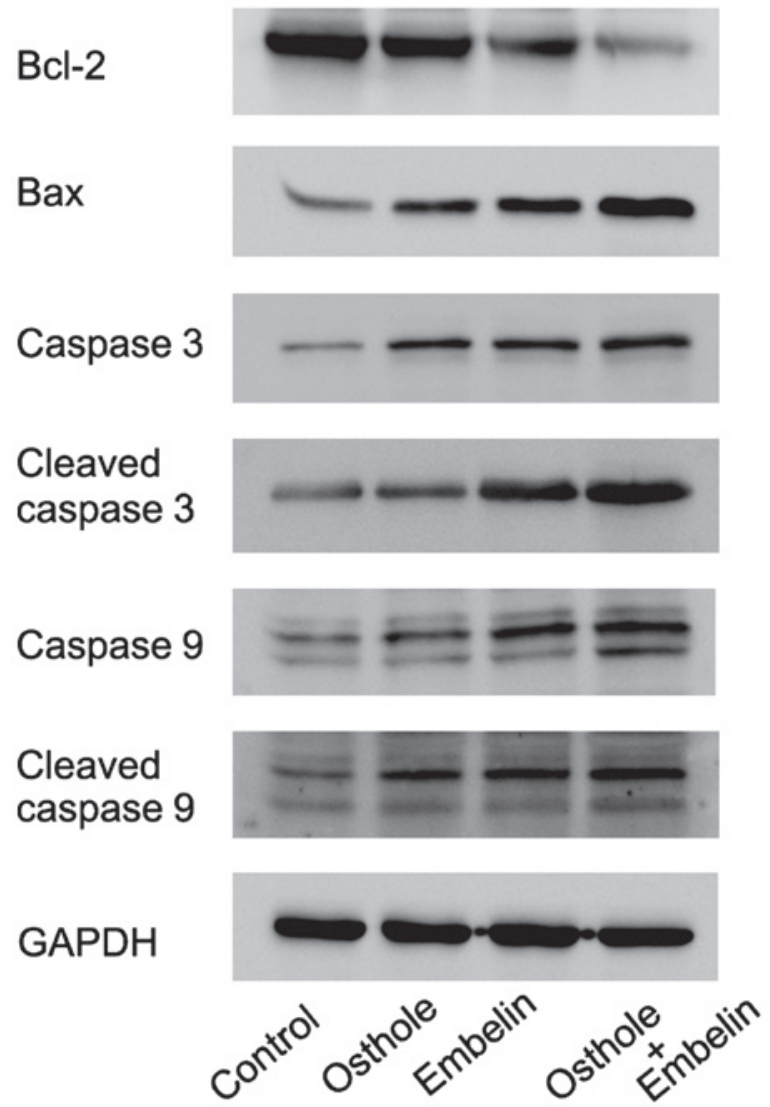

Figure 5. Combined effect of Osthole and Embelin on apoptosis-related proteins. Osthole or Embelin alone increased the expression of BAX, caspase-3, caspase- 9 , cleaved caspase- 3 and cleaved caspase- 9 , and decreased Bcl-2 levels following treatment. The Osthole and Embelin combination treatment had a synergistic effect on the regulation of these proteins. tosis-related proteins were screened following treatment with Osthole $(100 \mu \mathrm{M})$ and Embelin $(50 \mu \mathrm{M})$, alone or in combination. Compared with the control group, Osthole or Embelin alone increased the expression of BAX, caspase-3, caspase-9, cleaved caspase- 3 and cleaved caspase-9, while Bcl-2 levels were decreased following treatment (Fig. 5). Notably, the Osthole and Embelin combination treatment had a synergistic effect on the regulation of these proteins.

\section{Discussion}

Despite therapeutic advances, the high mortality rate of patients with NSCLC has not been substantially reduced over the past years. In order to improve the prognosis and survival rate, intensive efforts have been made to identify novel anticancer agents, and much attention has been drawn to herbal medicines, owing to their wide range of biological activities, low toxicity and minimal side effects. In the present study, we identified Osthole, a natural derivative of coumarin, as a novel antitumor agent in NSCLC. Moreover, we observed that Osthole had a synergistic effect on Embelin, which is another promising antitumor agent extracted from herbal medicines.

Osthole has long been used in traditional Chinese medicine for the treatment of eczema, cutaneous pruritus, trichomonas vaginalis infection and sexual dysfunction. Numerous previous studies have confirmed that Osthole possesses antitumor activity. It was reported that Osthole inhibited migration and invasion of breast cancer cells via suppression of matrix metalloproteinase (MMP)-2 (30). In addition, Osthole suppresses the migratory ability of human glioblastoma cells via the inhibition of focal adhesion kinase-mediated MMP-13 expression (31). Moreover, several studies have suggested that Osthole suppresses cell growth and induces apoptosis in leukemia and hepatocellular and cervical carcinoma cells $(13-15,32)$. We have previously reported that Osthole suppressed migration and invasion, and induced apoptosis in A549 lung cancer cells $(33,34)$. In addition, we observed that Osthole enhanced the anticancer effect of cisplatin in lung cancer cells in vitro (35). However, the possible mechanisms behind this remained unclear. In the present study, we demonstrated that Osthole induced apoptosis of A549 lung cancer cells via IAP inhibition.

IAPs are a group of structurally related proteins that were initially identified in baculoviruses (36). Mammalian IAPs block apoptosis either by binding and inhibiting caspases or through caspase-independent mechanisms (22). c-IAPs, XIAP and melanoma IAP bind caspase-3, -7 and -9 via the BIR domains (37-40), and induce their ubiquitination or neddylation via the RING domain $(41,42)$. Moreover, c-IAPs are positive regulators of cell proliferation (43), and the nuclear expression of c-IAP1 has been associated with advanced disease stages and poor patient prognosis in human cervical and esophageal squamous cell carcinomas and bladder cancers (44-46). To date, the overexpression of several IAPs has been detected in various cancers including NSCLC (22-24,27,47), and IAPs are significant targets for therapeutic intervention. It was previously reported that IAP-targeting therapy induces apoptosis and enhances chemotherapeutic activity against human lung cancer cells in vitro and in vivo $(27,47)$. In the present study, 
we evaluated the effect of Osthole on the IAPs by measuring the protein levels of XIAP, c-IAP1, c-IAP2 and Survivin. We observed that treatment of A549 lung cancer cells with various concentration of Osthole decreased the protein expression of XIAP, c-IAP1, c-IAP2 and Survivin, and increased Smac expression in a dose-dependent manner. These results indicate that Osthole induced apoptosis via regulation of IAP family proteins in a dose-dependent manner in NSCLC.

Embelin, a plant-based benzoquinone derivative, serves as a novel antitumor compound by inhibiting the activity of XIAP $(25,26,48-51)$. More recently, it was reported that Embelin induced apoptosis in NSCLC cells (52). Considering that Osthole and Embelin are low-toxicity natural compounds regulating the apoptosis of NSCLC, we questioned whether these two agents would have a synergistic effect on cancer therapy. We hence evaluated the combination effect of Osthole and Embelin on A549 cell apoptosis, and revealed that combination treatment exhibited a stronger apoptosis-inducing effect compared with monotherapy. In addition, compared with single-agent treatment, Osthole and Embelin combination treatment caused a greater change in apoptosis-related proteins including Bcl-2, BAX, caspase-3, caspase-9, cleaved caspase-3 and cleaved caspase-9. These results indicated that Osthole and Embelin have a synergistic effect on NSCLC treatment.

In conclusion, the present study demonstrated that Osthole inhibited proliferation and induced apoptosis in A549 lung cancer cells via the IAP family proteins in a dose-dependent manner. In addition, Osthole enhances the antitumor effect of Embelin. The present study indicates that the combination of Osthole and Embelin has potential clinical significance in the treatment of NSCLC.

\section{Acknowledgements}

The present study was supported by the Doctoral Scientific Research Foundation of Liaoning Province (Shenyang, China; grant no. 20121127). The study was approved by the ethics committee of Shengjing Hospital of China Medical University (Shenyang, China).

\section{References}

1. Jemal A, Bray F, Center MM, Ferlay J, Ward E and Forman D: Global cancer statistics. CA Cancer J Clin 61: 69-90, 2011.

2. Schiller JH, Harrington D, Belani CP, Langer C, Sandler A, Krook J, Zhu J and Johnson DH; Eastern Cooperative Oncology Group: Comparison of four chemotherapy regimens for advanced non-small-cell lung cancer. N Engl J Med 346: 92-98, 2002.

3. Pérez-Soler R: Individualized therapy in non-small-cell lung cancer: future versus current clinical practice. Oncogene 28 (Suppl 1): S38-S45, 2009.

4. Igney FH and Krammer PH: Death and anti-death: tumour resistance to apoptosis. Nat Rev Cancer 2: 277-288, 2002.

5. Los M, Burek CJ, Stroh C, Benedyk K, Hug H and Mackiewicz A: Anticancer drugs of tomorrow: apoptotic pathways as targets for drug design. Drug Discov Today 8: 67-77, 2003.

6. Reed JC: Apoptosis-based therapies. Nat Rev Drug Discov 1: 111-121, 2002.

7. Liao PC, Chien SC, Ho CL, Wang EI, Lee SC, Kuo YH, Jeyashoke N, Chen J, Dong WC, Chao LK and Hua KF: Osthole regulates inflammatory mediator expression through modulating $\mathrm{NF}-\kappa \mathrm{B}$, mitogen-activated protein kinases, protein kinase $\mathrm{C}$, and reactive oxygen species. J Agric Food Chem 58: 10445-10451, 2010.

8. Liu JH, Zschocke S, Reininger E and Bauer R: Inhibitory effects of Angelica pubescens f. biserrata on 5-lipoxygenase and cyclooxygenase. Planta Med 64: 525-529, 1998.
9. Matsuda H, Tomohiro N, Ido Y and Kubo M: Anti-allergic effects of cnidii monnieri fructus (dried fruits of Cnidium monnieri) and its major component, osthol. Biol Pharm Bull 25: 809-812, 2002.

10. Liu WB, Zhou J, Qu Y, Li X, Lu CT, Xie KL, Sun XL and Fei Z: Neuroprotective effect of osthole on MPP+-induced cytotoxicity in PC12 cells via inhibition of mitochondrial dysfunction and ROS production. Neurochem Int 57: 206-215, 2010.

11. Kuo PL, Hsu YL, Chang CH and Chang JK: Osthole-mediated cell differentiation through bone morphogenetic protein-2/p38 and extracellular signal-regulated kinase 1/2 pathway in human osteoblast cells. J Pharmacol Exp Ther 314: 1290-1299, 2005.

12. Huang RL, Chen CC, Huang YL, Hsieh DJ, Hu CP, Chen CF and Chang C: Osthole increases glycosylation of hepatitis B surface antigen and suppresses the secretion of hepatitis B virus in vitro. Hepatology 24: 508-515, 1996.

13. Yang LL, Wang MC, Chen LG and Wang CC: Cytotoxic activity of coumarins from the fruits of Cnidium monnieri on leukemia cell lines. Planta Med 69: 1091-1095, 2003.

14. Chou SY, Hsu CS, Wang KT, Wang MC and Wang CC: Antitumor effects of Osthol from Cnidium monnieri: an in vitro and in vivo study. Phytother Res 21: 226-230, 2007.

15. Riviere C, Goossens L, Pommery N, Fourneau C, Delelis A and Henichart JP: Antiproliferative effects of isopentenylated coumarins isolated from Phellolophium madagascariense Baker. Nat Prod Res 20: 909-916, 2006.

16. Deveraux QL and Reed JC: IAP family proteins - suppressors of apoptosis. Genes Dev 13: 239-252, 1999.

17. LaCasse EC, Baird S, Korneluk RG and MacKenzie AE: The inhibitors of apoptosis (IAPs) and their emerging role in cancer. Oncogene 17: 3247-3259, 1998.

18. Deveraux QL, Takahashi R, Salvesen GS and Reed JC: X-linked IAP is a direct inhibitor of cell-death proteases. Nature 388: 300-304, 1997.

19. Roy N, Deveraux QL, Takahashi R, Salvesen GS and Reed JC: The c-IAP-1 and c-IAP-2 proteins are direct inhibitors of specific caspases. EMBO J 16: 6914-6925, 1997.

20. Salvesen GS and Duckett CS: IAP proteins: blocking the road to death's door. Nat Rev Mol Cell Biol 3: 401-410, 2002.

21. Liston P, Fong WG and Korneluk RG: The inhibitors of apoptosis: there is more to life than $\mathrm{Bcl} 2$. Oncogene 22: 8568-8580, 2003.

22. Nachmias B, Ashhab Y and Ben-Yehuda D: The inhibitor of apoptosis protein family (IAPs): an emerging therapeutic target in cancer. Semin Cancer Biol 14: 231-243, 2004.

23. Tamm I, Kornblau SM, Segall H, Krajewski S, Welsh K, Kitada S, Scudiero DA, Tudor G, Qui YH, Monks A, et al: Expression and prognostic significance of IAP-family genes in human cancers and myeloid leukemias. Clin Cancer Res 6: 1796-1803, 2000.

24. Bertrand MJ, Milutinovic S, Dickson KM, Ho WC, Boudreault A, Durkin J, Gillard JW, Jaquith JB, Morris SJ and Barker PA: cIAP1 and cIAP2 facilitate cancer cell survival by functioning as E3 ligases that promote RIP1 ubiquitination. Mol Cell 30: 689-700, 2008.

25. Chitra M, Sukumar E, Suja V and Devi CS: Antitumor, anti-inflammatory and analgesic property of embelin, a plant product. Chemotherapy 40: 109-113, 1994.

26. Nikolovska-Coleska Z, Xu L, Hu Z, Tomita Y, Li P, Roller PP, Wang R, Fang X, Guo R, Zhang M, et al: Discovery of embelin as a cell-permeable, small-molecular weight inhibitor of XIAP through structure-based computational screening of a traditional herbal medicine three-dimensional structure database. J Med Chem 47: 2430-2440, 2004.

27. Hu Y, Cherton-Horvat G, Dragowska V, Baird S, Korneluk RG, Durkin JP, Mayer LD and LaCasse EC: Antisense oligonucleotides targeting XIAP induce apoptosis and enhance chemotherapeutic activity against human lung cancer cells in vitro and in vivo. Clin Cancer Res 9: 2826-2836, 2003.

28. Asselin E, Mills GB and Tsang BK: XIAP regulates Akt activity and caspase-3-dependent cleavage during cisplatin-induced apoptosis in human ovarian epithelial cancer cells. Cancer Res 61: 1862-1868, 2001.

29. Lu J, Huang Y, Zhao W, Marquez RT, Meng X, Li J, Gao X, Venkataramanan R, Wang Z and Li S: PEG-derivatized embelin as a nanomicellar carrier for delivery of paclitaxel to breast and prostate cancers. Biomaterials 34: 1591-1600, 2013.

30. Yang D, Gu T, Wang T, Tang Q and Ma C: Effects of osthole on migration and invasion in breast cancer cells. Biosci Biotechnol Biochem 74: 1430-1434, 2010.

31. Tsai CF, Yeh WL, Chen JH, Lin C, Huang SS and Lu DY: Osthole suppresses the migratory ability of human glioblastoma multiforme cells via inhibition of focal adhesion kinase-mediated matrix metalloproteinase-13 expression. Int J Mol Sci 15: 3889-3903, 2014. 
32. Okamoto $\mathrm{T}$, Kobayashi $\mathrm{T}$ and Yoshida S: Chemical aspects of coumarin compounds for the prevention of hepatocellular carcinomas. Curr Med Chem Anticancer Agents 5: 47-51, 2005.

33. Xu XM, Zhang Y, Qu D, Feng XW, Chen Y and Zhao L: Osthole suppresses migration and invasion of A549 human lung cancer cells through inhibition of matrix metalloproteinase-2 and matrix metallopeptidase-9 in vitro. Mol Med Rep 6: 1018-1022, 2012.

34. Xu X, Zhang Y, Qu D, Jiang T and Li S: Osthole induces G2/M arrest and apoptosis in lung cancer A549 cells by modulating PI3K/Akt pathway. J Exp Clin Cancer Res 30: 33, 2011.

35. Xu XM, Zhang Y, Qu D, Liu HB, Gu X, Jiao GY and Zhao L: Combined anticancer activity of osthole and cisplatin in NCI-H460 lung cancer cells in vitro. Exp Ther Med 5: 707-710, 2013.

36. Duckett CS, Nava VE, Gedrich RW, Clem RJ, Van Dongen JL, Gilfillan MC, Shiels H, Hardwick JM and Thompson CB: A conserved family of cellular genes related to the baculovirus iap gene and encoding apoptosis inhibitors. EMBO J 15 : 2685-2694, 1996.

37. Srinivasula SM, Hegde R, Saleh A, Datta P, Shiozaki E, Chai J, Lee RA, Robbins PD, Fernandes-Alnemri T, Shi Y and Alnemri ES: A conserved XIAP-interaction motif in caspase-9 and Smac/DIABLO regulates caspase activity and apoptosis. Nature 410: 112-116, 2001.

38. Liu Z, Sun C, Olejniczak ET, Meadows RP, Betz SF, Oost T, Herrmann J, Wu JC and Fesik SW: Structural basis for binding of Smac/DIABLO to the XIAP BIR3 domain. Nature 408: 1004-1008, 2000.

39. Eckelman BP, Drag M, Snipas SJ and Salvesen GS: The mechanism of peptide-binding specificity of IAP BIR domains. Cell Death Differ 15: 920-928, 2008.

40. Tenev T, Zachariou A, Wilson R, Ditzel M and Meier P: IAPs are functionally non-equivalent and regulate effector caspases through distinct mechanisms. Nat Cell Biol 7: 70-77, 2005

41. Huang HK, Joazeiro CA, Bonfoco E, Kamada S, Leverson JD and Hunter T: The inhibitor of apoptosis, cIAP2, functions as a ubiquitin-protein ligase and promotes in vitro monoubiquitination of caspases 3 and 7. J Biol Chem 275: 26661-26664, 2000.

42. Choi YE, Butterworth M, Malladi S, Duckett CS, Cohen GM and Bratton SB: The E3 ubiquitin ligase cIAP1 binds and ubiquitinates caspase- 3 and -7 via unique mechanisms at distinct steps in their processing. J Biol Chem 284: 12772-12782, 2009.
43. Samuel T, Okada K, Hyer M, Welsh K, Zapata JM and Reed JC: cIAP1 localizes to the nuclear compartment and modulates the cell cycle. Cancer Res 65: 210-218, 2005.

44. Imoto I, Tsuda H, Hirasawa A, Miura M, Sakamoto M, Hirohashi S and Inazawa J: Expression of cIAP1, a target for 11q22 amplification, correlates with resistance of cervical cancers to radiotherapy. Cancer Res 62: 4860-4866, 2002.

45. Tanimoto $\mathrm{T}$, Tsuda $\mathrm{H}$, Imazeki N, Ohno Y, Imoto I, Inazawa J and Matsubara O: Nuclear expression of cIAP-1, an apoptosis inhibiting protein, predicts lymph node metastasis and poor patient prognosis in head and neck squamous cell carcinomas. Cancer Lett 224: 141-151, 2005.

46. Che X, Yang D, Zong H, Wang J, Li X, Chen F, Chen X and Song X: Nuclear cIAP1 overexpression is a tumor stage- and grade-independent predictor of poor prognosis in human bladder cancer patients. Urol Oncol 30: 450-456, 2012.

47. Yang L, Mashima T, Sato S, Mochizuki M, Sakamoto H, Yamori T, Oh-Hara T and Tsuruo T: Predominant suppression of apoptosome by inhibitor of apoptosis protein in non-small cell lung cancer $\mathrm{H} 460$ cells: therapeutic effect of a novel polyarginine-conjugated Smac peptide. Cancer Res 63: 831-837, 2003.

48. Danquah M, Li F, Duke CB III, Miller DD and Mahato RI: Micellar delivery of bicalutamide and embelin for treating prostate cancer. Pharm Res 26: 2081-2092, 2009.

49. Sreepriya M and Bali G: Chemopreventive effects of embelin and curcumin against $\mathrm{N}$-nitrosodiethylamine/phenobarbital-induced hepatocarcinogenesis in Wistar rats. Fitoterapia 76: 549-555, 2005.

50. Dai Y, Qiao L, Chan KW, Yang M, Ye J, Ma J, Zou B, Gu Q, Wang J, Pang R, et al: Peroxisome proliferator-activated receptor-gamma contributes to the inhibitory effects of Embelin on colon carcinogenesis. Cancer Res 69: 4776-4783, 2009.

51. Heo JY, Kim HJ, Kim SM, Park KR, Park SY, Kim SW, Nam D, Jang HJ, Lee SG, Ahn KS, et al: Embelin suppresses STAT3 signaling, proliferation, and survival of multiple myeloma via the protein tyrosine phosphatase PTEN. Cancer Lett 308: 71-80, 2011.

52. Avisetti DR, Babu KS and Kalivendi SV: Activation of p38/JNK pathway is responsible for embelin induced apoptosis in lung cancer cells: transitional role of reactive oxygen species. PloS One 9: e87050, 2014. 